\title{
Inductive Processes, Heuristics, and Biases Modulated by High-Reliability Organizing (HRO) for COVID-19 and Disasters
}

Daved van Stralen, MD, FAAP, Thomas A. Mercer, RAdm, USN

\begin{abstract}
We view and understand the world through our internal logic, both public and private internal logic. The logic of practice differs by the frame of reference - a fixed point or within the flux of events, which can have "cosmology episodes" that collapse sensemaking. We have different perceptions and capabilities from the different reference frames, Eulerian and Lagrangian specificities, Euclidean, and topological spaces. When approaching a situation, all we have is observation, induction, and the capability to learn through action. Because people have limited time and knowledge, they must make inferences from the information they have available. We almost universally use heuristic, subjective approaches for better decision-making for complex, interactive problems and processes. Heuristics work through the nearness of information between the old problem-solution and the new problem, a topological space. In routine operations, we are susceptible to heuristic bias, yet error corrects this heuristic bias counterintuitively. We have found four predominant heuristics that cause consequential bias and interfere with effective decision-making: availability, representativeness, confirmation bias, and over-conservative revision. Motivated reasoning, a fifth bias but not from a heuristic, overly scrutinizes information that conflicts with closely held beliefs. Unless we assume that every word and behavior could instantly be wrong, we can too easily begin treating our treatments.
\end{abstract}

\section{"Interviewing people for After Action}

Reports or following a serious event, the authors initially hear stories that don't match how people act in threatening circumstances (1). The stories only make sense through publicly accepted beliefs, heuristics, and logic. A supportive challenge to the description of their actions, while the authors let the person know they had been in similar situations, quickly changes the narrative to one more consistent with human experience."

\section{Introduction}

Interviewing people for After Action Reports or following a serious event, the authors initially hear stories that don't match how people act in threatening circumstances (1). The stories only make sense through publicly accepted beliefs, heuristics, and logic. A supportive challenge to the description of their actions, while the authors let the person know they had been in similar situations, quickly changes the narrative to one more consistent with human experience.

Several areas that a person transforms for acceptability are their private logic, how they learn through action, sensemaking shortcuts, and reason.

We view and understand the world through our internal logic, both public and private internal logic. Our public logic informs our stories and what we openly expect in a situation. Our intimate explanations to ourselves and a few trusted others come from our private logic.

"This is not a trivial distinction; private logic is quite visible in the first minutes or hours after a tragedy as events expose the raw beliefs of each person. Because we otherwise have no access to people's intimate internal logic, some behaviors and beliefs may not make sense to us unless we appreciate this private internal logic."

This is not a trivial distinction; private logic is quite visible in the first minutes or hours after a tragedy as events expose the raw beliefs of each person. Because we otherwise have no access to people's intimate internal logic, some behaviors and beliefs may not make sense to us unless we appreciate this private internal logic. One author (DvS) has extensive experience as the first person to arrive at an emergency, observing this change in behaviors and words as family or friends arrive.

We more easily observe this in the hospital following an accident, such as near-drowning when one parent had sole custody of the child. Within several days a narrative develops faulting the custodial parent. Leigh Aveling, the hospital chaplain, explained how this shatters the family's dynamics. During the first several days, family or friends enter and gain greater influence. Aveling and the author approached the next drowning admission differently. Within the PICU, they isolated the parents from family and friends, with the chaplain offering spiritual counseling and the intensivists explaining childhood behaviors and accidents.

After 48 hours, the extended family could visit in the presence of parents. The paternal grandparents openly blamed the mother.

NEONATOLOGY TODAY is interested in publishing manuscripts from Neonatologists, Fellows, NNPs and those involved in caring for neonates on case studies, research results, hospital news, meeting announcements, and other pertinent topics.

Please submit your manuscript to: LomaLindaPublishingCompany@gmail.com 
The father tenderly placed his arm around her and said it was an accident; no one intended it to happen. He continued defending the mother throughout the PICU admission. The child survived.

The rules of their narrative affect their understanding of the event as it unfolds, how they interpret the results, and how they tell their story. This is how they explain but also how they understand. We will hear this internal logic and the shift from private to the public when we listen to their description or during an interview immediately after events have occurred. First, they make sense to themselves; then, the story seems to change as they begin to make sense to others. This is not falsity; listen for their internal logic, as it will help explain their actions and how they will act next time. "It is after the fact that we retrospectively begin to attribute specific reasons for the decisions that we made," Capt. Chesley "Sully" Sullenberger (personal communication).

Academicians studying the logic of practice from outside the flux and trajectory of events attempt to normalize cognition and behaviors without the necessary access to inner mental states impaired by stress and threat that are manifested as contingently linked behaviors (2-4). Detached observation and identification of abstract properties, necessary for scientific objectivity, conceal the situational reasoning and intent of the operator (4-6). The internal logic of operations that individuals utilize becomes unrecognized and inaccessible (7).

\section{"Detached observation and identification of abstract properties, necessary for scientific objectivity, conceal the situational reasoning and intent of the operator (4-6). The internal logic of operations that individuals utilize becomes unrecognized and inaccessible (7)."}

When unrecognized within a system, this concealment impedes the development of experts (6). The academic focus on abstract properties diminishes or further conceals the development of expert performance which, paradoxically, comes from experience in particular situations rather than abstractions $(6,8)$.

Renaud Vidal (9), research engineer, Aix Marseille University, observed the "presumption of logic becomes a presumption of control." HRO decentralization and distribution of autonomy to field operators can undermine the necessary presumption logic and control. The loss of confidence in the system destabilizes the confidence-cautiousness balance. Bob Bea, Professor Emeritus, Civil Engineering, University of California, Berkeley, maintains a database of over 600 engineering failures and has studied some of the largest engineering disasters in recent U.S. history (10). Bea has also had the experience of a novice placed in a dangerous context.

"Some of the work we have done has been able to reach [field operators] and capture their perceptions and ideas for improvements $=$ worker/operator empowerment. However, many of my colleagues have used methods and approaches that have depowered the worker/operators because of the dramatic differences in 'language' and 'motives."'

Bob Bea, 8/30/2005, personal communication
The unsupported belief that objectivity and distance from practice outweigh subjectivity and proximity can lead researchers, leaders, and managers to consider operators as biased, imprecise, and nonrational. The organization and human practices can then be made more rigorous through scientific knowledge with scientific rationality (4). Rejection of the logic of practice used by operators enacts unrecognized restraints that become visible in a crisis (11, 12 ), a dangerous form of latent failure.

Yet within the NICU, the environment can become unpredictable from time compression and abrupt changes in structure. The Neonatologist must work with imperfect information in flux-the internal logic of events changes. Threats impair the mind, which, if unmodulated, can easily become unrecognized and even normalized (13).

Karl Weick (14) described how these "cosmology episodes" collapse sensemaking and leadership. This occurred even with seasoned wildland firefighters during the 1949 Mann Gulch Fire. Such abrupt breaches in the environment involve the entire group or organization. What is rational and logical in structured, predictable environments becomes harmful during a cosmology episode. Actions or events may appear irrational solely because we do not recognize the system's internal logic. We likely continue our use of classical, scientific logic even as the system's internal logic changes.

This forms a gap between what executives and administrators expect based on concepts and plans developed from public logic and the actual behaviors that emerge from private logic.

\section{"Our presence in or out of a system is more than a different frame of reference. We have different perceptions and capabilities. For Newtonian mechanics, physicists must make specific the frame of reference when they study natural phenomena."}

\section{Private logic}

Our presence in or out of a system is more than a different frame of reference. We have different perceptions and capabilities. For Newtonian mechanics, physicists must make specific the frame of reference when they study natural phenomena. There is an assumption of Euclidean space, yet more likely, the operator is in a topological space. For our purposes, we shall identify the space we describe.

Time is integral to emergencies and crises. For example, removing the time component from stress and the stressor makes them uncontrollable and inescapable. Uncontrollability is a recognized cause of stress and inescapability; the inability to maintain 'safety distance' is a recognized cause of fear $(2,15)$. The metaphors we use for stress come from physics and the study of solids. Stress in colloids and fluids differ in response to pressure, solids deform or break while many fluids are incompressible, and shear stress, solids deform, and fluids flow. (Compressible fluids develop discontinuities called shocks.) We limit our use of metaphor and analogy, staying close to the inductive principles for using an analogy.

There are two specifications for fluid flow that align with experience (Table 1), Eulerian and Lagrangian specifications. Eulerian specifications align with business management studies, while La- 
grangian specifications align with psychological studies.

\begin{tabular}{|l|l|l|}
\hline & Eulerian, quantitative & $\begin{array}{l}\text { Langrangian, } \\
\text { qualitative }\end{array}$ \\
\hline Frame & $\begin{array}{l}\text { External, fixed point } \\
\text { Focus on the specific } \\
\text { location }\end{array}$ & $\begin{array}{l}\text { Within flow } \\
\text { Focus on the } \\
\text { individual moving } \\
\text { parcel }\end{array}$ \\
\hline Properties & Flow & Trajectory \\
\hline Flow analysis & $\begin{array}{l}\text { Fluid velocity, volume, } \\
\text { rate } \\
\text { Multiple, fixed positions }\end{array}$ & $\begin{array}{l}\text { Continuous mea- } \\
\text { sure } \\
\text { Parcel velocity } \\
\text { with position, pres- } \\
\text { sure }\end{array}$ \\
\hline Characteristics & $\begin{array}{l}\text { Rate of change of sys- } \\
\text { tem Variables fixed at a } \\
\text { point }\end{array}$ & $\begin{array}{l}\text { Individual parcels } \\
\text { Along individual } \\
\text { trajectories }\end{array}$ \\
\hline
\end{tabular}

Table 1: Eulerian and Lagrangian Specifications (16)

The specific relation between the operator and the particular situation constitutes the logic of underlying practice $(4,17)$. The purpose of logic for the operator in an HRO is to update mental patterns of observed reality for an accurate representation to guide actions in the world $(4,7,18)$, reasoning in transition to develop expert performance (19), open up a universe of possibilities (20), and to grasp ambiguity to sustain ongoing projects (21).

\section{"When the logic of practice is made visible, other factors lead to its suppression. Leaders and managers may believe field operators cannot grasp the necessary content or exercise the necessary judgment. This becomes self-fulfilling when the organization maintains operators at the competence skill level, the level of abstract learning, and below the practice of the particular situation."}

When the logic of practice is made visible, other factors lead to its suppression. Leaders and managers may believe field operators cannot grasp the necessary content or exercise the necessary judgment. This becomes self-fulfilling when the organization maintains operators at the competence skill level, the level of abstract learning, and below the practice of the particular situation. There is little need for rationality or logic of practice at the competence level because procedures become routines and standards. A high-turnover workforce becomes interchangeable (22).

Epistemic logic is concerned with logical approaches to knowledge and belief, how operators perceive and understand the actual world. People may have believed as a conviction that everything they believe is true, or only believe what is objectively true, that is, independent of their subjectivity. There are small but conceptually important differences between the frames of view.
Knowledge of the situation depends on the frame of reference (3, 23): the perfect (objective) external, the imperfect external, and the subjective internal points of view. The external views compare to Eulerian specifications, while the internal point of view is more akin to the Lagrangian view.

The perfect external view represents assumptions of omniscience and perfect knowledge of the situation, uninvolved with events. This view also assumes access to how operators are feeling and thinking. We believe the models developed cannot be wrong.

The imperfect external view represents someone outside the situation but without full knowledge of the situation. This models leadership more closely from a distance. We assume these operational models could be wrong.

\section{"The imperfect external view represents someone outside the situation but without full knowledge of the situation. This models leadership more closely from a distance. We assume these operational models could be wrong."}

\section{Inductive processes}

Induction is to learn through action. To approach any situation or to experience a situation that abruptly envelopes us, at first, all we have for learning is observation. It is the observation that begins the inductive process and how we gain knowledge. Leonhard Euler (24) described this, "We should use such a discovery as an opportunity to investigate more than exactly the properties discovered and to prove or disprove them; in both cases, we may learn something useful." Through induction and common sense, we find the regularity and coherence behind the visible surface; we discover the "engine" driving the problem (25-27).

John Boyd, an influential U.S. Air Force military tactician, described straightforward mental approaches for us to "act relatively free or independent of any debilitating external influences" when our mental patterns may not represent observed reality. "Creativity is related to induction, synthesis, and integration since we proceed from unstructured bits and pieces to a new general pattern or concept. We call such action a creative or constructive induction...this creative induction is the separation of the particulars from their previous domains by the destructive deduction. Without this un-structuring, creating a new structure cannot proceedsince the bits and pieces are still tied together as meaning within unchallenged domains or concepts, John Boyd (18).

Boyd's response to a disruption of observed reality parallels Weick's sensemaking perspective that operators create what they focus on through repeated cycles. For Weick's sensemaking, the operator distinguishes cues within an ambiguous event to use for enactment toward a resolution that restores the disrupted activity $(28,29)$. Both authors describe the rapidity of inductive and deductive processes as responses to disrupted cosmology. John Dewey describes the same functions of inductive and deductive processes but over a longer time period of discovery:

"When pains are taken to make each aspect of the movement as accurate as possible, the movement toward building up the idea is known as inductive discovery (induction, for short); the movement toward developing, applying, and testing, as deductive proof 
(deduction, for short). While induction moves from fragmentary details (or particulars) to a connected view of a situation (universal), the deduction begins with the latter and works back again to particulars, connecting them and binding them together. The inductive movement is toward discovering a binding principle; the deductive is toward testing, confirming, refuting, and modifying it based on its ability to interpret isolated details into a unified experience. So far as we conduct each of these processes in the light of the other, we get valid discovery or verified critical thinking, John Dewey (30).

Induction ensures safety and reliability. Knowledge from observation "must be carefully distinguished from the truth; it is gained by induction," Leonhard Euler (24). Inductive processes are the chance to "correct our ideas when they are wrong, to adapt them to reality," George Pólya (31). These creative inductive processes move the system from disorder toward order and a goal-oriented system $(18,32)$.

\section{"A disaster or pandemic COVID 19 brings} the environment into our medical work area. We experience complexity, loss of structure, and lose definability - characteristics of the ill-structured problem (33). Business management and medical decisionmaking approaches support computational routines such as algorithms for decisions and actions. Such computational routines, however, do not support learning."

\section{Heuristics}

A disaster or pandemic COVID 19 brings the environment into our medical work area. We experience complexity, loss of structure, and lose definability - characteristics of the ill-structured problem (33). Business management and medical decision-making approaches support computational routines such as algorithms for decisions and actions. Such computational routines, however, do not support learning. On the other hand, heuristics can search the complex or poorly structured environments of a disaster to increase accuracy in decision-making and make our working model more detailed $(34,35)$. Heuristics are how we learn while solving ill-structured problems (36).

Heuristics and ambiguity

During a disaster, Bayes' Theorem can update the probabilities of events from updated information. This assumes we have sufficient time and that we can generate the information. Bob Bea, Professor Emeritus, Civil Engineering, University of California, Berkeley (8/8/2007, personal communication), (37) underscored that Bayes' Theorem "should only be used to update epistemic or model-parameter uncertainties." These uncertainties occur from the model's imperfections and are fundamentally 'information sensitive,' that is, increasing information reduces the uncertainty. Claude Shannon's Information Entropy describes how choice, acting to change uncertainty to certainty, creates information (38).

Heuristics operate outside this system by making the model more accurate in real-time (34). In a disaster, we work with "inherent or natural uncertainties that are fundamentally information insensitive" (Bob Bea, 8/8/2007, personal communication). Acquiring more information does not necessarily reduce uncertainty. Nevertheless, heuristics can increase accuracy and add detail (34).

Ambiguity corrupts accuracy and detail. "Ambiguity may lead us to construct a world that, while supported by evidence, is not true. We select evidence and interpretations for their plausibility, but later events show we were wrong" (39). However, Karl Weick (21) embraces ambiguity - to reduce ambiguity, you must initially increase it. Through the engagement of the complex and ambiguous environment, we then organize the situation. The active engagement of ambiguity creates understanding, organization, and communication, like Shannon's statement that when we make choices in uncertainty, we create information (38). From our experience and the use of heuristics, we learn through engagement and can then manage the ambiguity and complexity of a disaster.

\section{Heuristic problem solving}

For complex, interactive problems and processes, we almost universally use heuristic, subjective approaches for better decisionmaking $(36,40)$. Heuristics are the mental operations we use to learn how to solve problems, improve our performance, make use of our intuition and insight $(25,36)$, make inferences about the environment (31), and identify and correct errors (41). Heuristics are built from our experience and modeling, watching other people solve problems $(25,41)$.

Heuristics work through the nearness of information between the old problem-solution and the new problem (42). Thinking while acting and learning by doing utilize this topological information while trial and error occur when the distance between experience and the situation is too great or non-existent. Topological distances are relational rather than hierarchical.

We cannot equate the rapidity of making a connection with the presence, utility, or effectiveness of a heuristic. Speed of connection does come from a heuristic, but it is the availability heuristic discussed below. However, practical, common-sense decisionmaking evaluates the consequences of actions, tempering the speed of association (27). For innovative decision making, "a major part of the decision-making task [is] to discover what consequences will follow" (43).

\section{"Heuristics work through the nearness of information between the old problem- solution and the new problem (42). Thinking while acting and learning by doing utilize this topological information while trial and error occur when the distance between experience and the situation is too great or non-existent."}

Heuristic, "serving to discover or find out," describes provisional reasoning to discover the problem's solution and is often based on induction or analogy (25). Heuristics would be specific to a situation and, for the embedded problem, derive rationality from the structure of the environment $(44,45)$. We use heuristics when we don't know. Acting when we do not know relies on error identifica- 
tion and correction to maneuver through events $(27,32,46)$.

Herbert Simon and Allen Newell (36) recognized that people have limited time and knowledge; therefore, they must make inferences from the available information. This means contingently ignoring part of the information while using partially relevant information when we don't know which part is relevant $(27,47)$. Heuristics are a large part of practical, common-sense problem solving (27).

\section{Heuristic Bias}

Heuristics are the rules we use for intuitive predictions, like the more statistically based Bayes' Theorem. Daniel Kahneman and Amos Tversky studied heuristic rules and subsequent biases by comparing them to Bayes' Theorem's statistical prediction. Specifically, they evaluated category and numerical prediction (48).

But what if we wanted to predict influence. "What action can I take to influence the situation?" The uncertainties within a disaster are not "information sensitive," imperfections that can be reduced with Bayes' Theorem. The uncertainties in a disaster are inherent to entropy in an open system. Such uncertainties are fundamentally "information insensitive." Information is less to create a better model than it is to guide actions.

Heuristics, when they don't take us to a satisfactory result (33), can keep us trapped in a failed bias (48). For example, when we learn a dynamic skill, moving from novice to proficient, we use the new information to extend our performance $(6,49)$. Failures will increase as we gain motor and cognitive control. Once our performance becomes stable, our instructor takes us to a higher level of training. The cyclic increase and decrease in performance as we add skills is regression to the mean. An indirect consequence comes when the instructor complements the student for improvement; the student pushes the skill and begins to fail. The instructor interprets the new failure because of the complement. The opposite occurs with improved performance after criticism (48). A teaching culture develops where complements are not given, and criticism is good teaching technique.

\section{"Decision-making in academic studies is to decide for the answer, a normative result. Too great a distance from the normative value is an error $(35,48) . "$}

Decision-making in academic studies is to decide for the answer, a normative result. Too great a distance from the normative value is an error $(35,48)$.

Decision-making in a volatile situation is to move toward safety, bring control, generate information, give meaning, and reduce ambiguity. Decision-making works through reciprocal feedback; response to an action is interpreted and guides the next action, much like John Boyd's OODA Loop (50). In uncertainty and volatility, accuracy drives our beliefs and decisions and leads to more accurate inferences (35). Algorithmic strategies for normative outcomes use information and computation $(26,33)$ while relying on a stable model of an actual world

Heuristics as psychological bias, normative with a singular decision, can favor algorithmic approaches such as protocols and rules. Heuristics for decisions to increase accuracy bring about engagement and sharing of freshly generated information. Reciprocal decision-making relies on heuristics for decisions, error for correction, and consequences for guidance $(21,33,35,46)$. The decision doesn't end until the threat has abated.

\section{Heuristics and psychology}

Heuristics are also understood to be mental operations for prediction and judgment under uncertainty. Heuristics are economical and effective in these situations but lead to systematic and predictable errors and biases $(51,52)$. Academic studies measure single or 'final' decisions made from beliefs and predictions, using probability as a standard. For example, the representativeness heuristic measures the bias that what you see represents what is actual. The bias comes from connecting what you see to a stereotype that you have. Acting during a dynamic, complex situation, you would use representativeness as a starting point, then use inductive processes to distinguish bias from the truth (24), probing the situation and your hypothesis in the form of the OODA loop (53). Also, the prediction has a different meaning in preparation for and responding to an abrupt event. While heuristic reasoning is good, Pólya underscores that heuristic reasoning is not rigorous proof (25). Like much of our experience in dangerous situations, you use it without fully trusting it

In training novices, we have found four predominant heuristics (Table 2) that cause consequential bias and interfere with effective decision-making: availability, representativeness, confirmation bias, and over-conservative revision. Motivated reasoning, a fifth bias but not from a heuristic, prevents accepting information that contradicts a strongly held belief. This is not confirmation bias.

\section{"In training novices, we have found four predominant heuristics (Table 2) that cause consequential bias and interfere with effective decision-making: availability, representativeness, confirmation bias, and over-conservative revision. Motivated reasoning, a fifth bias but not from a heuristic, prevents accepting information that contradicts a strongly held belief. This is not confirmation bias."}

\begin{tabular}{|l|l|}
\hline Heuristic & Bias \\
\hline Availability & $\begin{array}{l}\text { What you think of first is most im- } \\
\text { portant }\end{array}$ \\
\hline Representativeness & What you see represents events \\
\hline Confirmation bias & Seek supporting evidence \\
\hline Overconservative revision & More information to stop than start \\
\hline Motivated reasoning & $\begin{array}{l}\text { Overly scrutinize evidence against } \\
\text { strongly held beliefs }\end{array}$ \\
\hline
\end{tabular}

Table 2: Heuristics and biases

Availability, also called frequency bias, leads us to accept our first impression. Availability bias also occurs when redundant measurements of variables influence our perceptions. Availability also biases us toward precision and the use of numbers as quantitative information over qualitative values.

Amos Tversky and Daniel Kahneman (51) described the impor- 
tant role 'imaginability' has toward our view of the risks of an adventurous expedition. Imagine the contingencies with which you are not equipped to cope. Although this is more of a frame problem, it represents how a new frame can lead to inordinate concern from staff. "If many [contingencies] are vividly portrayed, the expedition can be made to appear exceedingly dangerous, although the ease with which disasters are imagined need not reflect their actual likelihood. Conversely, the risk involved in an undertaking may be grossly underestimated if some possible dangers are either difficult to conceive or simply do not come to mind." We see this in inexperienced staff and families.

\section{"Conversely, the risk involved in an undertaking may be grossly underestimated if some possible dangers are either difficult to conceive or simply do not come to mind." We see this in inexperienced staff and families."}

Tversky and Kahneman, however, focused decision-making on threats one could conjure, or even worse, worry of not conjuring enough threats. Operators in dangerous contexts seek capabilities for threats, particularly capabilities they can generalize to unforeseen threats or that extend operations into novel situations $(41,54,55)$.

We can demonstrate availability by asking someone to spell the word "folk." Then ask, "What is the white of an egg called?" The answer you had made available to the brain is "yolk." We experience availability with consultants because the information from their specialty is more available to them. Acceptance of our first impression simplifies the situation. We, too easily, stop developing more structure. Mentally listing 3-4 causes of the situation helps discipline the mind to continue thinking after the first acceptable answer.

"Acceptance of the suggestion in its first form is prevented by looking into it more thoroughly. Conjectures that seem plausible at first sight are often found unfit or even absurd when their full consequences are traced out. Even when reasoning out the bearings of a supposition does not lead to rejection, it develops the idea into a form in which it is more [apt] to the problem," John Dewey (30).

Representativeness, closely tied in with complexity and "reluctance to simplify," leads us to regard partial information as if it were complete information: what you see represents what is happening. This is a difficult one to break because practical, commonsense problem solving uses partial information (27), which is also all we have when we begin to engage. When we recognize the bias of representativeness, we can reevaluate the situation and update and revise our beliefs.

Confirmation bias derives from cognitive dissonance. To reduce dissonance, we search for confirming information. We look for evidence that will support our conclusions while ignoring disconfirming, discrepant data. Confirmation and availability biases are insidiously dangerous; an individual stops considering alternatives.

Overconservative revision biases us to require more information to stop an action than we initially required to start. We continue treatments long past the point when we would not have initiated the treatment. Once we start a treatment, we find it hard to stop, even when the reason to treat is gone.

The author (DvS) assumed care for a child with a 'do not resus- citate order' due to failure of cardiovascular support. The treating and consulting teams supported the withdrawal of medical support from the patient. Vascular access was lost, effectively terminating support. The author placed a central venous catheter from a supraclavicular approach and confirmed placement by chest $\mathrm{x}$ ray. In the early-morning hours, the child went into abrupt respiratory distress. A chest $x$-ray showed fluid in the chest on the side with the catheter. Further studies revealed that the catheter was alongside, rather than inside, the vein. All the required fluids and medications were entering the chest cavity rather than the bloodstream. Oddly, the child had improved. The author discontinued all medications under the assumption that the medications were not necessary. The child continued to improve.

Medication to strengthen the heart had constricted blood vessels and caused kidney failure. This led to medications to dilate the blood vessels and to improve kidney function. Other medications also became involved to help maintain physiological balance. We had been treating our treatments.

It is easier to identify the symptoms of "treating the treatment" in others rather than in your own care. The author resolved "treating the treatments" on several patients during evaluation for an organ transplant. Consultants and second opinions play an important role in high-risk environments since they bring new points of view.

\section{"Error corrects heuristic bias. Though counterintuitive, the individual in these situations considers every action could be wrong. The author (DvS) served on a fire rescue ambulance in South Los Angeles ten years after the Watts Riots. The Crips and Pirus (later the Bloods) were moving north. Recognizing a gang member by clothing, behavior, stance, and countenance influenced our approach."}

Error corrects heuristic bias. Though counterintuitive, the individual in these situations considers every action could be wrong. The author (DvS) served on a fire rescue ambulance in South Los Angeles ten years after the Watts Riots. The Crips and Pirus (later the Bloods) were moving north. Recognizing a gang member by clothing, behavior, stance, and countenance influenced our approach. The gang 'uniform' had yet to form. However, we had to discern the gang member from the 'wannabe' attempting to join or the youth adopting the gang appearance for their protection. Each needed to be treated differently. It was the feedback during our interactions that guided us. To stick with the wrong approach could lead to our injury or mistreating a youth trying to get by and stay in school. Every word and behavior could instantly be wrong.

\section{Cognitive science}

Artificial intelligence was modeled from human cognition. Herbert Simon differentiated human thinking between well-structured problems that humans and computers could solve with algorithms and ill-structured problems that humans could solve with heuristics but computers could not (36). Artificial intelligence worked to make computers operate like human thinking. From this research, the field of cognitive psychology developed (56). Computers then 
became a metaphor for cognitive scientists to understand human thinking (57), bringing along easily understood algorithms as thinking models. As a result, algorithms are often the method proffered to work with complex situations and with a large amount of information for decisions.

We urge caution regarding the reliance on algorithms and the over-scrutiny of heuristics for operations during a disaster.

\section{Motivated reasoning}

Motivated reasoning is the spontaneous default mechanism for defending their prior attitudes and actively challenging arguments incongruent with their strongly held beliefs. People are unaware of their use of motivated reasoning, which comes from motives to achieve an accurate conclusion or maintain a specific conclusion (58).

A person firmly holds their desired conclusion even if it involves rejecting disconfirming evidence (58-60). Rather than emotion or identity, this is reasoning toward a preferred conclusion affecting forming impressions, determining beliefs and attitudes, evaluating evidence, and making decisions $(58,61)$. Analytical sophistication and education do not reduce the presence of motivated reasoning (62).

Motivated beliefs are unconsciously directed toward a goal (62). Protecting a self-serving conclusion comes from their prior beliefs; the conclusions seem more plausible. Motivation appears to have its effects through cognitive processes rather than emotion (58). The individual will attempt to be rational, constructing an "objective" justification persuasive to a dispassionate observer. This can involve creatively combining knowledge to construct new, logical beliefs supporting their desired conclusion. They do not realize their reasoning processes have biased their thinking (58).

We commonly find this in lay science and medical issues, that once they formed an impression, they have motivated reasoning to keep it. Scientific and health literacy then fail (63). It is difficult to counter their arguments. They may be receptive when the message is congruent with their preexisting goals or when their motivation comes from a deep existential need (60). Still, the direct challenge can evoke strong emotions, even physical anger, and outrage $(58,62)$. This is a clear sign you have infringed on a protected, cherished belief.

Individuals protect cherished beliefs for several reasons $(58,62)$. Motivated reasoning enhances self-efficacy against a problem of self-control or gives utility for beliefs to counter a perceived weakness in a desired trait. Motivated reasoning also protects personal and social identity. Selective updating by information avoidance and asymmetric processing of good and bad information protects these beliefs (62).

This is the danger of motivated reasoning to over-scrutinize new information that disconfirms cherished beliefs. Abrupt threats, Weick's loss of cosmology, do not respond to cherished beliefs. In the search for solutions, heuristics help if we calibrate our decisions through early error detection and correction. We must rapidly distinguish ambiguous cues calibrated to actual events (28, 29), not beliefs. We gain accuracy through inductive processes and heuristics.

Motivation for accuracy takes greater cognitive effort for reasoning, attending to relevant information, deeper processing, and more complex rules (58). This is similar to the approach described by Simon for the ill-structured problem (36), where greater accuracy is achieved through heuristics and reciprocal $(50)$ decision making $(35,36)$. The concern of avoiding a wrong judgment and drawing the wrong conclusion while more careful cognitive processing parallels $\mathrm{HRO}$ reasoning. A consequence is the reduction of cognitive biases (58).

\section{Conclusion}

We do not give up our judgment and creativity in a dangerous context or lose our thinking under time compression. We can use inductive processes to learn from the environment as we act. We can use heuristics to develop solutions for the embedded, ill-defined problem through vigilance toward error, using error to define our operational envelope (46). Anomalies and disconfirming evidence are valuable; we search for them. Counterintuitively, by constantly proving ourselves wrong, we become closer to being right.

\section{"We do not do this through speed or shortcuts but by increasing our tempo. Boyd described the methods and benefits of a faster tempo: the ability to transition more rapidly than events change, develop more repertoires of action, free and open communication, interactive support, increased information sources to select from, and generation of new ideas that can be rapidly tested (64). Our private logic can then become our public logic."}

We do not do this through speed or shortcuts but by increasing our tempo. Boyd described the methods and benefits of a faster tempo: the ability to transition more rapidly than events change, develop more repertoires of action, free and open communication, interactive support, increased information sources to select from, and generation of new ideas that can be rapidly tested (64). Our private logic can then become our public logic.

"Morally, we interact with others by avoiding mismatches between what we say we are, what we are, and the world we have to deal with," John Boyd (64).

\section{References:}

1. van Stralen D, McKay S, Williams GT, Mercer TA. Tactical Improvisation: After-Action/ Comprehensive Analysis of the Active Shooter Incident Response by the San Bernardino City Fire Department December 2, 2015. San Bernardino, CA: San Bernardino County Fire Protection District; 2018.

2. van Stralen D, Mercer TA. During Pandemic COVID-19, the High-Reliability Organization (HRO) Identifies Maladaptive Stress Behaviors: The Stress-Fear-Threat Cascade. Neonatology Today. 2020;15(11):113-24. doi: 10.51362/neonatology.today/2020111511113124.

3. van Stralen D. Pragmatic High-Reliability Organization (HRO) During Pandemic COVID-19. Neonatology Today. 2020;15(4):3-9.

4. Sandberg J, Tsoukas H. Grasping the logic of practice: Theorizing through practical rationality. Academy of management review. 2011;36(2):338-60.

5. Dreyfus HL. What could be more intelligible than everyday intelligibility? Reinterpreting division I of Being and Time in the light of division II. Bulletin of Science, Technology \& Society. 2004;24(3):265-74.

6. Benner P. From Novice to Expert: Excellence and Power in 
Clinical Nursing Practice. Menlo Park, CA: Addison-Wesley; 1984.

7. van Stralen D, Inozu B, Byrum S. High Reliability for a Highly Unreliable World: Preparing for Code Blue through Daily Operations in Healthcare. North Charleston, SC: CreatSpace Publishing; 2017.

8. Dreyfus HL, Dreyfus SE. From Socrates to expert systems: The limits of calculative rationality. In: C. $M, A$. $H$, editors. Philosophy and technology II. Boston Studies in the Philosophy of Science. 90. Berlin, Germany: Springer, Dordrecht; 1986. p. 111-30.

9. Vidal R. Managing Uncertainty: The Engineer, the Craftsman and the Gardener. Journal of Contingencies and Crisis Management. 2015;23(2):106-16. doi: 10.1111/14685973.12081.

10. Prud'homme A. Bob Bea, the Master of Disaster. Men's Journal 2013:72-5.

11. Weick KE. Enactment and Organizing. The Social Psychology of Organizing. Second ed. New York, NY: McGraw-Hill, Inc.; 1979. p. 147-69.

12. Weick KE. Enacted sensemaking in crisis situations Journal of management studies. 1988;25(4):305-17.

13. van Stralen D, Mercer TA. Pragmatic High-Reliability Organizations (HRO) Modulate the Functions of Stress and Fear Behaviors During Pandemic COVID-19: The Stress-FearThreat Cascade. Neonatology Today. 2020;15(10):126-34. doi: 10.51362/neonatology.today/2020101510126134.

14. Weick KE. The collapse of sensemaking in organizations: The Mann Gulch disaster. Administrative science quarterly. 1993;38(4):628-52.

15. van Stralen D, Mercer TA. Pandemic COVID-19, the HighReliability Organization (HRO), and the Ecology of Fear. Neonatology Today. 2020;15(12):129-38. doi: 10.51362/ neonatology.today/2020121512129138.

16. Price J.F. Lagrangian and eulerian representations of fluid flow: Kinematics and the equations of motion: MIT OpenCourseWare; 2006.

17. Dewey J. The sphere of application of the excluded middle. The Journal of Philosophy. 1929;26(26):701-5.

18. Boyd J. Destruction and creation. Fort Leavenworth, KS: U.S. Army Comand and General Staff College, 1976.

19. Benner P. Using the Dreyfus model of skill acquisition to describe and interpret skill acquisition and clinical judgment in nursing practice and education. Bulletin of science, technology \& society. 2004;24(3):188-99.

20. Wolfberg A. Full-spectrum analysis: $A$ new way of thinking for a new world. Military Review. 2006;86(4):35-42.

21. Weick KE. Ambiguity as Grasp: The Reworking of Sense. Journal of Contingencies and Crisis Management. 2015;23(2):117-23. doi: 10.1111/1468-5973.12080.

22. Benner P. From novice to expert. American Journal of nursing. 1982;82(3):402-7.

23. Aucher G. An Internal Version of Epistemic Logic. Studia Logica. 2010;94(1):1-22. doi: 10.1007/s11225-010-9227-9.

24. Euler L. Opera Omnia, ser. 1, vol. 2. In: Pólya G, editor. Mathematics and plausible reasoning: Induction and analogy in mathematics. 1. Princeton, NJ: Princeton University Press; 1761.

25. Pólya G. How to solve it: a new aspect of mathematical method. Garden City, N.Y.: Doubleday; 1945.

26. Nadel SF. The Foundations of Social Anthropology. London,
UK: Routledge; 1951.

27. van Stralen D, Mercer TA. Common Sense High Reliability Organizing (HRO) in the Response to COVID-19. Neonatology Today. 2021;16(7):90-102. doi: 10.51362/neonatology. today/2021716790102.

28. Sandberg J, Tsoukas H. Making sense of the sensemaking perspective: Its constituents, limitations, and opportunities for further development. Journal of Organizational Behavior. 2015;36(S1):S6-S32. doi: 10.1002/job.1937.

29. Weick KE. Sensemaking in organizations. Dickens G, editor. Thousand Oaks, CA: Sage; 1995.

30. Dewey J. How we think. New York, NY: D. C. Heath \& Co.; 1910.

31. Pólya G. Mathematics and plausible reasoning: Induction and analogy in mathematics. Princeton, NJ: Princeton University Press; 1954.

32. van Stralen D, Mercer TA. The Art of Neonatology, the Art of High Reliability as a Response to COVID-19. Neonatology Today. 2021;16(2):74-83. doi: 10.51362/neonatology. today/202121627483.

33. Simon HA. The structure of ill structured problems. Artificial Intelligence. 1973;4(3-4):181-201. doi: 10.1016/00043702(73)90011-8.

34. Simon HA. The sciences of the artificial: MIT press; 2019.

35. Neth H, Gigerenzer G. Heuristics: Tools for an uncertain world. Emerging trends in the social and behavioral sciences: Wiley Online Library; 2015. p. 1-18.

36. Simon HA, Newell A. Heuristic Problem Solving: The Next Advance in Operations Research. Operations Research. 1958;6(1):1-10. doi: 10.1287/opre.6.1.1.

37. Prud'homme A. Bob Bea, the Master of Disaster. Men's Journal. 2013;5:72-5.

38. Shannon CE. A Mathematical Theory of Communication. Bell System Technical Journal. 1948;27(3):379-423. doi: 10.1002/j.1538-7305.1948.tb01338.x.

39. Van Stralen D. Ambiguity. Wiley Online Library; 2015.

40. Orr GE. Combat Operations C3I: Fundamentals and Interactions. Maxwell Air Force Base, Montgomery, AL: Airpower Research Institute, USAF; 1983.

41. van Stralen D, Mercer TA. High Reliability Organizing (HRO) is the Extension of Neonatology during Pandemic COVID-19. Neonatology Today. 2021;16(5):97-109. doi: 10.51362/neonatology.today/2021516597109.

42. Bickhard MH, Campbell RL. Topologies of learning and development. New Ideas in Psychology. 1996;14(2):111-56.

43. Simon $H$. The executive's responsibility for innovation. Chicago, IL: University of Chicago; 1957. p. 4.

44. Gigerenzer G, Goldstein DG. Reasoning the fast and frugal way: models of bounded rationality. Psychol Rev. 1996;103(4):650-69. Epub 1996/10/01. doi: 10.1037/0033295x.103.4.650. PubMed PMID: 8888650.

45. Gigerenzer G. Why Heuristics Work. Perspect Psychol Sci. 2008;3(1):20-9. Epub 2008/01/01. doi: 10.1111/j.17456916.2008.00058.x. PubMed PMID: 26158666.

46. van Stralen D, Gambino W. Error as a Faulty Failure Signal. Neonatology Today. 2020;15(9):114-7. doi: 10.51362/neonatology.today/20209159114117.

47. Minsky M. A framework for representing knowledge. In: Winston PH, editor. The Psychology of Computer Vision. New York, NY: 211-277; 1975.

48. Kahneman D, Tversky A. On the psychology of prediction. 
Psychological Review. 1973;80(4):237-51. doi: 10.1037/ h0034747.

49. Dreyfus SE, Dreyfus HL. The Scope, Limits, and Training Implications of Three Models of Aircraft Pilot Emergency Response Behavior. Berkeley, CA: University of California, Berkeley, Center OR; 1979 February 1979. Report No.: ORC 79-2 Contract No.: ORC 79-2.

50. van Stralen $D$, Mercer TA. High-Reliability Organizing (HRO), Decision Making, the OODA Loop, and COVID-19. Neonatology Today. 2021;16(8):86-96.

51. Tversky A, Kahneman D. Judgment under Uncertainty: Heuristics and Biases. Science. 1974;185(4157):1124-31. Epub 1974/09/27. doi: 10.1126/science.185.4157.1124. PubMed PMID: 17835457.

52. Tversky A, Kahneman D. Judgment Under Uncertainty: Heuristics and Biases. Springfield, VA: Oregon Research Institute, Advanced Research Projects Agency OoNR; 1973 Contract No.: AD-767 426.

53. Boyd J. A discourse on winning and losing. Maxwell AFB, Alabama: Air University Press; 2018.

54. van Stralen D, Mercer TA. High Altitude Climbing, High Reliability, COVID-19, and the Power of Observation. Neonatology Today. 2021;16(1):68-79. doi: 10.51362/neonatology. today/20211616879.

55. van Stralen D, Mercer TA. High-Reliability Organizing (HRO) in the COVID-19 Liminal Zone: Characteristics of Workers and Local Leaders. Neonatology Today. 2021;16(4):90-101. doi: 10.51362/neonatology.today/2021416490101.

56. Starbuck WH. Karl E. Weick and the dawning awareness of organized cognition. Management Decision. 2015;53(6):1287-99. doi: 10.1108/md-04-2014-0183.

57. Robins RW, Gosling SD, Craik KH. Macroscope: Psychological Science at the Crossroads. American Scientist. 1998;86(4):310-3.

58. Kunda Z. The case for motivated reasoning. Psychological bulletin. 1990;108(3):480.

59. Kraft PW, Lodge M, Taber CS. Why people "don't trust the evidence" motivated reasoning and scientific beliefs. The ANNALS of the American Academy of Political and Social Science. 2015;658(1):121-33.

60. Cotter RG, Lodge M, Vidigal $R$. The boundary conditions of motivated reasoning. The Oxford Handbook of Electoral Persuasion: Oxford University Press, USA; 2020. p. 66.

61. Epley N, Gilovich T. The Mechanics of Motivated Reasoning. Journal of Economic Perspectives. 2016;30(3):133-40. doi: 10.1257/jep.30.3.133.

62. Bénabou R, Tirole J. Mindful Economics: The Production, Consumption, and Value of Beliefs. Journal of Economic Perspectives. 2016;30(3):141-64. doi: 10.1257/jep.30.3.141.

63. Druckman JN, Leeper TJ, Slothus R. Motivated Responses to Political Communications: Framing, Party Cues, and Science Information In: Lavine H, Taber CS, editors. The Feeling, Thinking Citizen: Essays in Honor of Milton Lodge. Routledge Studies in Political Psychology. 5. N.Y., NY: Routledge; 2018. p. 124-50.

64. Boyd J. The Strategic Game of ? and ? In: Hammond GT, editor. A discourse on winning and losing. Maxwell AFB, Alabama: Air University Press; 2018. p. 255-314.
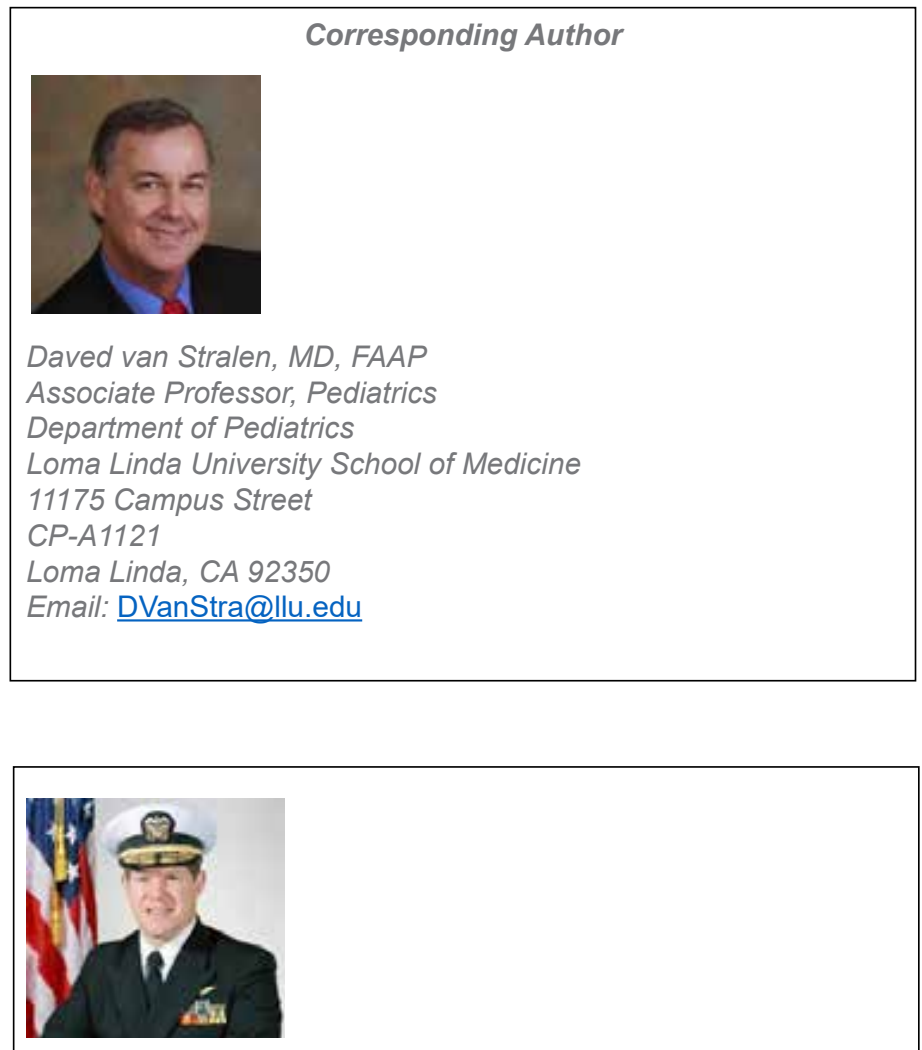

Thomas A. Mercer

Rear Admiral

United States Navy (Retired)

\section{Acknowledgments}

Karl Weick, Rensis Likert Distinguished University Professor of Organizational Behavior and Psychology, Emeritus, University of Michigan

Sean D. McKay, Element Rescue, LLC

Errol van Stralen, Ancora Education

William Gambino, CIV, DoD

William J. Corr, formerly with the Los Angeles City Fire Department, now deceased

Disclosures: The authors have no relevant disclosures 